\title{
CORPO E BELEZA EM IMAGENS E NAS FALAS DAS CRIANÇAS: APRENDER A SER MENINO OU MENINA NA EDUCAÇÃO INFANTIL
}

\author{
Narda Helena Jorosky, Maria de Fátima Salum Moreira \\ Universidade do Oeste Paulista - UNOESTE, Mestrado em Educação, Presidente Prudente, SP. E-mail: \\ hjorosky@hotmail.com
}

\begin{abstract}
RESUMO
Este artigo apresenta o projeto de pesquisa em desenvolvimento no Mestrado em Educação da UNOESTE - Universidade do Oeste Paulista. Essa investigação é de natureza qualitativa e caracterizada como estudo de caso. Realiza-se em uma sala com crianças de quatro anos de idade, em uma instituição de educação infantil do Estado do Paraná. Trata das representações das crianças sobre corpo e beleza, e de suas associações com as diferenças de gênero. O objetivo é analisar os significados e juízos que atribuem às ideias de "corpo belo" e "corpo feio", e se existem especificidades e/ou diferenças, quando se trata de um corpo identificado como de menino ou de menina. Baseia-se em uma abordagem teórica e metodológica amparada em estudos sociológicos, históricos e culturais efetuados no âmbito da Sociologia da Infância e da Cultura Visual. Os instrumentos utilizados são: observação participante, entrevistas semiestruturadas com as crianças; diário de campo para registro de suas ações; levantamento e descrição de imagens presentes na instituição. Os dados produzidos serão confrontados entre si e com a bibliografia teórica e temática. Espera-se contribuir para a compreensão dos processos que produzem as diferenças, hierarquias e desigualdades nas instituições de educação infantil.

Palavras-chave: Infância. Gênero. Corpo. Cultura visual. Sociologia da Infância.
\end{abstract}

\section{BODY AND BEAUTY IN IMAGES AND IN FALAS CHILDREN: LEARN TO BE BOY OR GIRL IN EARLY CHILDHOOD EDUCATION}

\begin{abstract}
This qualitative research characterized as a case study, will be held in a room with children four years of age in an early childhood institution in a municipality of Paraná. Brings the study of representations of children about body and beauty, and its productions of meanings to gender differences. The goal is to analyze their understanding and judgments to the ideas of "body beautiful" and "ugly body." It has a theoretical and methodological approach supported by sociological, historical and cultural studies and studies of sociology of childhood and Visual Culture. The instruments are: participant observation, semi-structured interviews with children; field diary to record the actions; survey and description of images present in the institution. The data produced will be compared between themselves and with the theoretical literature and theme. It is expected to contribute to the understanding of the processes that produce the differences, hierarchies and inequalities.
\end{abstract}

Keywords: Childhood. Gender. Body. Visual culture. Sociology of Childhood. 


\section{INTRODUÇÃO}

Esta pesquisa propõe uma investigação que envolve discutir a infância e as crianças, na perspectiva da relação entre corpo, gênero e cultura visual. Mais propriamente, irá analisar como crianças de uma Instituição de Educação infantil significam e expressam suas visões sobre corpo e beleza, enfatizando as interfaces com as relações de gênero.

De caráter qualitativo, na forma de estudo de caso, o trabalho será realizado em uma Instituição de Educação Infantil no município de Ribeirão Claro, no Estado do Paraná, que conta com cerca de 130 alunos, porém, focada nas percepções e manifestações das crianças sobre as imagens com representações de corpos presentes no espaço escolar como um todo - dentro e fora da sala: cartazes, revistas, livros didáticos, livros de literatura infantil.

Entende-se que as manifestações infantis são provenientes de uma cultura própria das crianças. Suas expressões, em variadas linguagens, decorrem da relação com a cultura da qual fazem parte. Ou seja, pode-se dizer que os significados atribuídos às imagens presentes no ambiente que habitam em seu cotidiano influenciam seus modos de relacionamento, identidade, autoimagem e, igualmente, comportamento corporal.

Neste trabalho, serão adotados os estudos de gênero e da cultura visual relacionados a corpo e beleza, para proceder às análises das imagens na Instituição de Educação Infantil e de seus significados para as crianças. Isso implica "[...] pensar nas crianças como vivendo em contextos específicos, com experiências específicas e em situações de vida real” (WALSH; GRAUE, 2003, p. 22).

A pesquisa também tem como fundamento as formulações teóricas de gênero propostas por Jean Scott (1990), para quem o gênero está articulado à vinculação entre saber e poder. A autora assevera que o gênero deve ser visto como uma forma primeira de dar significação e legitimidade às relações de poder e pressupõe a consideração do caráter relacional das distinções sociais baseadas na diferença biológica dos sexos. Nessa perspectiva analítica, não basta simplesmente identificar as diferenças implícita ou explicitamente colocadas nas operações discursivas, mas é necessário voltar-se sobre o modo como se constituem os mecanismos dessas próprias operações, no interior das quais se produzem significados para as hierarquias e desigualdades de gênero (MOREIRA, 1996, p. 4).

As perspectivas teóricas da Sociologia da Infância consideram as crianças como atores sociais, com base em sua inserção geracional na fase denominada infância. Diante disso, pretendese fazer uma aproximação desse mundo infantil, por meio do diálogo e escuta, da observação de suas ações e interações, tanto entre as próprias crianças como entre elas e os adultos, no espaço 
educacional. Serão investigadas quais são as representações ou visões que meninos e meninas, entre 4 e 5 anos, apresentam sobre o corpo e a beleza e, em especial, quando atinentes a homens ou mulheres. Saber ouvir as crianças e buscar suas interpretações leva a pensar, com Rocha (2008, p.46), que é preciso "[...] nessa escuta confrontar, conhecer um ponto de vista diferente daquele que nós seríamos capazes de ver e analisar no âmbito do mundo social de pertença dos adultos".

As imagens estão constantemente na vida das crianças, seja no ambiente escolar, seja na casa, na família, de sorte que em todo o seu entorno é possível percebê-las. As imagens penetram as impressões e pensamentos de modo imperceptível, sem que se possa dar conta de suas implicações na vida pessoal e coletiva. Atualmente, com a participação intensa do consumo visual, no cotidiano, intensificam-se igualmente os resultados de seus efeitos na produção de subjetividades, nas representações de corpo, beleza e gênero das crianças. A importância primordial da cultura visual é mediar o processo de como olhamos e como nos olhamos e, dessa maneira, contribuir para a produção de mundos, de maneira que a sua perspectiva "[...] não é um quê (objeto, imagens), nem um como (método para interpretar o que vemos). É o espaço de interação entre o que vemos e o como somos vistos por aquilo que vemos" (HERNÁNDEZ, 2007, p. 77).

As imagens, como entidades visuais concretas, produzem impacto, podendo ser vistas como expressões de determinado contexto cultural e como um modo particular de ver e expressar o mundo. É no cotidiano infantil e não só no ambiente escolar que pode existir um paralelo entre culturas geradas, conduzidas e também dirigidas pelos adultos e as culturas construídas nas interações entre as crianças, as quais constituirão os mundos culturais da infância, conforme salienta Sarmento (2002).

Em síntese, o objetivo geral é analisar os mecanismos socioculturais que produzem os significados para as diferenças de gênero entre crianças de quatro anos de idade, nas interfaces com suas representações sobre corpo e beleza e com as imagens presentes nos espaços educacionais da infância. O projeto de pesquisa já está formalmente cadastrado na Coordenadoria Central de Pesquisa (CCPq) e no Comitê de Ética em Pesquisa (CEP) sendo avaliado e aprovado nas duas instâncias da Universidade do Oeste Paulista - UNOESTE de Presidente Prudente/SP em fevereiro de 2015.

\section{METODOLOGIA}

Tendo como principal referência para o estudo das crianças os aportes teóricos da Sociologia da Infância, a investigação se baseia em estudos sociológicos, históricos e culturais, 
dialogando principalmente com os seguintes teóricos e autores: Sarmento e Pinto (1997), James, Jenk e Prout (1998) e Almeida (2009). A cultura visual é tratada conforme o conceito empregado por Fernando Hernández (2007), enquanto o conceito de gênero, segundo Scott (1990), Nicholson (1994) e Várikas (1994).

As interpretações se fundamentarão, primeiramente, nas teorias da linguagem e dos enunciados de Bakhtin (1997), as quais indicam que todo exercício de fala deve ser contextualizado social e culturalmente. Isso implica entender as ideias e compreensões expressas pelas crianças como constituintes e representativas de um determinado contexto, ao mesmo tempo em que são social e culturalmente por ele produzidas.

As análises serão baseadas no cruzamento dos diversos discursos - orais e imagéticos expressos em falas das crianças e nas imagens produzidas dispostas na instituição, seguindo-se o princípio do autor de que os lugares nos quais os textos se cruzam e se interpenetram podem ser considerados como "centros" organizadores do conjunto dos enunciados. Assim, "[...] o centro organizador de toda enunciação, de toda expressão, não é interior, mas exterior, está situado no meio social que envolve o indivíduo" (BAKHTIN, 1990, p.121). Os estudos culturais de Certeau (1994) serão igualmente empregados para a discussão das relações entre representação e apropriação (CERTEAU, 1994).

Os procedimentos metodológicos sustentam-se na sequência indicada por Minayo: 1) a leitura flutuante do material; 2) o contato exaustivo com os enunciados selecionados; 3) a leitura detalhada e a distribuição em temas; 4) a análise temática e conceitual das categorias de análise iniciais e daquelas que surgirem, no decorrer do trabalho (MINAYO,1992; 2004).

Nesse sentido, as características que permitirão o processo da investigação serão apoiadas em: observação participante, entrevistas semiestruturadas com as crianças, em grupo ou individualmente; diário de campo para registro das ações desenvolvidas entre as crianças e entre elas e os adultos, no cotidiano da instituição; observação e descrição do espaço e seus usos, com ênfase no movimento e relação entre as crianças e nas imagens ali dispostas, levantamento e descrição analítica de materiais visuais presentes na instituição: cartazes, vídeos, materiais didáticos, fotos, objetos, brinquedos, desenhos etc. Os dados produzidos serão confrontados entre si e com a bibliografia teórica e temática.

Dentre os procedimentos, destaco as observações diretas e sistemáticas em sala de aula e demais espaços da Instituição utilizados pelas crianças, não somente dos entrevistados e participantes da pesquisa, na chegada, recreio, momentos de lazer e saída; registro permanente de diário de campo; realização das dinâmicas com as crianças e também entrevistas; aplicação das 
entrevistas semiestruturadas com o professor responsável pela sala de aula onde será realizada a investigação; aplicação de um questionário socioeconômico e cultural, com questões semiabertas para o(a)s familiares responsáveis pelas crianças e entrevista semiestruturada; devolutiva da pesquisa às crianças, familiares e profissionais da Instituição de Educação Infantil.

\section{DISCUSSÃO}

Têm-se, como objeto de pesquisa, os saberes socialmente construídos pelas crianças sobre corpo, gênero e sexualidade, concretizando-se por uma proposta de estudo numa pesquisa de caráter qualitativo, do tipo estudo de caso e etnográfico, a qual adota por fundamentação teórica os estudos da Sociologia da Infância, com ênfase nos aspectos culturais e simbólicos das experiências sociais.

Sabe-se que, através do corpo, há interações com o meio natural, social, com a cultura, com os adultos e outras crianças e, assim, é fundamental refletir sobre como a criança se vê e como percebe o outro, a partir dos padrões de beleza instalados. Para isso, a cultura visual é um fundamental elemento, quando se leva em conta todo e qualquer tipo de imagem a que as crianças têm acesso, em seu dia a dia.

Estudos, como os de Hernandez (2007; 2010), Cunha (2005), Meyer, Soares (2008) e Andrade (2008), afirmam que a imagem e a mídia, de uma maneira global, exercem um poder sobre a visão corporal da criança, as formas de enxergar o outro e a si mesma, atuando sobre os modos de organização social infantil. A produção intensiva e intencional das imagens com foco no corpo e na beleza ofertadas pelas esferas comerciais, midiáticas, culturais e escolares, com seus múltiplos serviços e produtos destinados às crianças, implica a construção de suas identidades e diferenças de gênero.

Ao se inquirir a respeito de como os conceitos de "corpo belo" e "corpo feio" são constituídos e quais seriam os seus efeitos, em termos de práticas de discriminação e violência, observamos que homens e mulheres, meninos e meninas, são igualmente atingidos em relação a isso, acarretando diversas formas de distinção social e cultural de gênero, afetando as relações entre as crianças e delas com os adultos, bem como a organização social como um todo. Embora atingidos igualmente, meninos e meninas são afetados de forma diferente, visto que existem expectativas diversas em função do gênero, isto é, os padrões de beleza masculinos não coincidem totalmente com os femininos.

Na sociedade atual, agravam-se as implicações das imagens sobre o "corpo ideal", em face da divulgação de padrões de comportamento e beleza ditados pela sociedade de consumo. As 
crianças são um público privilegiado, de sorte que a presença midiática é extremamente forte em suas rotinas. Essas relações podem se tornar violentas, ofensivas e discriminatórias, ao se pensar nas imagens privilegiadas no âmbito cultural onde as crianças estão inseridas.

Ao se pensar a criança como produtora de uma cultura própria, enfatiza-se ainda o caráter social que faz com que qualquer agente seja, ao mesmo tempo, produto e produtor de cultura. Nessa perspectiva, ao abordar o conceito de socialização na infância, Corsaro enfatiza que esta consiste em um processo de "reprodução interpretativa", quer dizer, que esta não se limita a processos de adaptação ou reprodução do mundo adulto ou da cultura dominante. Trata-se de um movimento ativo de construção e reconstrução, em que as crianças são participantes na produção e transformação social e cultural (CORSARO, 2002).

\section{CONCLUSÃO}

Se as instituições educacionais e escolares são os lugares que oferecem maiores possibilidades para as práticas da sociabilidade, nesse período, reconhece-se que ali as crianças irão encontrar inúmeras referências para a formação de sua identidade social, seus valores, cognição, afetividade e outros elementos relacionados ao seu desenvolvimento humano, cultural e social.

Além disso, tenho como pressuposto que a construção das identidades e diferenças de gênero são social, cultural e historicamente produzidas. Tal construção, contudo, ocorre a partir do seu entrecruzamento com outros marcadores, os quais constituem as relações entre indivíduos e sociedade: raça/etnia, classe, nacionalidade, sexualidade etc. Todos esses elementos são associados às construções simbólicas que significam a relação entre corpo e sociedade.

Ademais, aponta-se como fator determinante de tais fenômenos a incidência de múltiplos discursos que regulam, normatizam e instauram saberes que produzem "verdades" baseadas em padrões anatômicos e biológico-sexuais também concebidos como fixos. Embora muitas pesquisas indiquem que as crianças constroem suas identidades de gênero, segundo classificações fixas e dicotômicas de masculinidade e feminilidade, tenho como hipótese que elas também realizam interpretações singulares, em conformidade com as especificidades de suas culturas infantis.

São com tais pressupostos e conceitos sobre as crianças, as culturas da infância e a cultura visual que esta pesquisa visa a compreender como as imagens presentes da vida cotidiana das crianças de 4 a 5 anos interferem na construção de suas representações e significados sobre os modelos de beleza corporal e como estão em concordância com a construção de suas identidades e diferenças de gênero. 


\section{REFERÊNCIAS}

ALMEIDA, A. N. de. Para uma sociologia da Infância: Jogos de olhares, pistas para a investigação. Lisboa: ICS. Imprensa de Ciências Sociais, 2009.

ANDRADE, S. S. Mídia, corpo e educação: a ditadura do corpo perfeito. In: MEYER, D. E.; SOARES, R. F.R. Corpo, Gênero e Sexualidade. Porto Alegre: Mediação, 2004.

BAKHTIN, M. Marxismo e filosofia da linguagem. 3. ed. Tradução de Michel Lahud e Yara F. Vieira. São Paulo: Hucitec, 1990

CERTEAU, M. A invenção do cotidiano: 1, Artes de fazer. Petrópolis: Vozes, 1994.

CORSARO. W. Entrada no campo, aceitação e natureza da participação nos estudos etnográficos com crianças pequenas. Revista Educação e Sociedade, Campinas, v. 26, n. 91, p.443-464, maio/ago. 2005. Disponível em: http://www.cedes.unicamp.br. Acesso em: 12 out. 2007.

CUNHA, S. R. V. da. Educação e Cultura Visual: uma trama entre imagens e infância. 2005. Tese (Doutorado) - Faculdade de Educação, UFRGS, Porto Alegre-RS, 2005. Disponível em: http://www.lume.ufrgs.br/handle/10183/79457?show=full. Acesso em: 03 maio 2015.

GRAUE, M. E.; WALSH, D. J. Investigação etnográfica com crianças: teorias e métodos e ética. Tradução de Ana Maria Chaves. Lisboa: Fundação Calouste Gulbenkian, 2003.

HERNÁNDEZ, F. Catadores da cultura visual: transformando fragmentos em nova narrativa educacional. Revisão técnica: Jussara Hoffman e Susana Rangel Vieira da Cunha; tradução de Ana Duarte. Porto Alegre: Mediação, 2007.

JAMES, A.; JENKS, C.; PROUT, A. O corpo e a infância. In: KOHAN, W. O.; KENNEDY, D. Filosofia e Infância: Possibilidades de um encontro. 2. ed., Petrópolis: Vozes, 2000. p.207-238.

MEYER, D. E; SOARES, R. F.R. Corpo, Gênero e Sexualidade. Porto Alegre: Mediação, 2008.

MINAYO, M.C.S. Fase de trabalho de campo. O desafio do conhecimento, v. 7, p. 105-156, 1992.

MINAYO M.C.S. O desafio do conhecimento: pesquisa qualitativa em saúde. 8.ed. São Paulo: Hucitec, 2004.

PINTO, M.; SARMENTO, M. J. (Coord.). As crianças: contextos e identidades. Universidade do Minho: Centro de Estudos da Criança, 1997.

ROCHA, E. A. C. Por que ouvir as crianças? Algumas questões para um debate científico multidisciplinar. In: CRUZ, S. H. V. (Org.). A criança fala: a escuta de crianças em pesquisas. São Paulo: Cortez, 2008. p. 43-51.

SCOTT, J. Gênero: uma categoria útil de análise histórica. Educação e Sociedade, Porto Alegre, v. 6 n. 2, p. 5-22, jul./dez.1990.

VÁRIKAS, E. Gênero, Experiência e Subjetividade: a propósito do desacordo Tilly - Scott. Tradução de Ricardo Augusto Vieira. Cadernos Pagu, Campinas (SP), v.3, p.63-84,1994. 